\title{
Dorsal Root Ganglia Macrophages Maintain Osteoarthritis Pain
}

\author{
${ }^{1}$ Ramin Raoof, ${ }^{1}$ Christian Martin Gil, ${ }^{1}$ Floris P.J.G. Lafeber, ${ }^{2}$ Huub de Visser, ${ }^{2}$ Judith Prado, ${ }^{1}$ Sabine Versteeg, ${ }^{1}$ \\ Mirte N. Pascha, ${ }^{1}$ Anne L.P. Heinemans, ${ }^{1}$ Youri Adolfs, ${ }^{3}{ }^{\circledR}$ Jeroen Pasterkamp, ${ }^{3}$ John N. Wood, ${ }^{4}$ \\ Simon C. Mastbergen, ${ }^{2}$ and ${ }^{\circledR}$ Niels Eijkelkamp ${ }^{1}$ \\ ${ }^{1}$ Center for Translational Immunology, University Medical Center Utrecht, Utrecht University, 3584 CX Utrecht, The Netherlands, ${ }^{2}$ Department of \\ Rheumatology and Clinical Immunology, Regenerative Medicine Center, University Medical Center Utrecht, Utrecht University, 3584 CX Utrecht, \\ The Netherlands, ${ }^{3}$ Department of Translational Neuroscience, Utrecht Brain Center, University Medical Center Utrecht, Utrecht University, 3584 \\ CX Utrecht, The Netherlands, and ${ }^{4}$ Molecular Nociception Group, Department of Biology, University College London, London WC1E 6BT, England
}

Pain is the major debilitating symptom of osteoarthritis $(\mathrm{OA})$, which is difficult to treat. In OA patients joint tissue damage only poorly associates with pain, indicating other mechanisms contribute to $\mathrm{OA}$ pain. Immune cells regulate the sensory system, but little is known about the involvement of immune cells in OA pain. Here, we report that macrophages accumulate in the dorsal root ganglia (DRG) distant from the site of injury in two rodent models of OA. DRG macrophages acquired an M1-like phenotype, and depletion of DRG macrophages resolved OA pain in male and female mice. Sensory neurons innervating the damaged knee joint shape DRG macrophages into an M1-like phenotype. Persisting OA pain, accumulation of DRG macrophages, and programming of DRG macrophages into an M1-like phenotype were independent of $\mathrm{Na}_{\mathrm{v}} 1.8$ nociceptors. Inhibition of M1-like macrophages in the DRG by intrathecal injection of an IL4-IL10 fusion protein or M2-like macrophages resolved persistent $\mathrm{OA}$ pain. In conclusion, these findings reveal a crucial role for macrophages in maintaining $\mathrm{OA}$ pain independent of the joint damage and suggest a new direction to treat OA pain.

Key words: chronic pain; macrophage; osteoarthritis; sensory neuron

Significance Statement

In OA patients pain poorly correlates with joint tissue changes indicating mechanisms other than only tissue damage that cause pain in OA. We identified that DRG containing the somata of sensory neurons innervating the damaged knee are infiltrated with macrophages that are shaped into an M1-like phenotype by sensory neurons. We show that these DRG macrophages actively maintain $\mathrm{OA}$ pain remotely and independent of joint damage. The phenotype of these macrophages is crucial for a pain-promoting role. Targeting the phenotype of DRG macrophages with either M2-like macrophages or a cytokine fusion protein that skews macrophages into an M2-like phenotype resolves OA pain. Our work reveals a mechanism that contributes to the maintenance of $\mathrm{OA}$ pain distant from the affected knee joint and suggests that dorsal root ganglia macrophages are a target to treat osteoarthritis chronic pain.

Received July 10, 2020; revised July 29, 2021; accepted Aug. 2, 2021

Author contributions: R.R., F.L., J. Pasterkamp, J.N.W., S.C.M., and N.E. designed research; R.R., C.M.G., H.d.V., J. Prado, S.V., M.N.P., A.L.P.H., and Y.A performed research; J. Pasterkamp contributed unpublished reagents/analytic tools; R.R., C.M.G., H.d.V., M.N.P., Y.A., and N.E. analyzed data; R.R. and N.E. wrote the paper.

This work was supported by the European Union Horizon 2020 Research and Innovation Program under Marie Skłodowska-Curie Grants 642720 and 814244 . N.E. and J. Prado were supported by the Life Sciences Seed Grant from Utrecht University. F.L. and S.C.M. were supported by the Dutch Arthritis Association (Grant LLP-9), and R.J.P. was supported by the Netherlands Organization for Scientific Research. J.N.W. was supported by Versus Arthritis (grant 29150). We thank the University Medical Center Utrecht Multidisciplinary Investigation of Neural Disorders facility for help with light-sheet microscopy and iDISCO tissue clearing, Michiel van der Vlist for reading the manuscript and discussions, Roeland Lokhorst for help with the dynamic weight-bearing analysis, Mirjam Maas for isolation of bone marrow-derived macrophages, and Megan Opstal for technical assistance with stainings of DRGs.

N.E. is a cofounder of and consultant for Synerkine Pharma, and F.L. is a consultant for Synerkine Pharma. All the other authors declare no competing financial interests.

Correspondence should be addressed to Niels Eijkelkamp at n.eijkelkamp@umcutrecht.nl.

https://doi.org/10.1523/JNEUROSCI.1787-20.2021

Copyright $\odot 2021$ the authors

\section{Introduction}

Osteoarthritis $(\mathrm{OA})$ is a highly prevalent disease affecting one in eight adults with a large and increasing societal burden (Hunter et al., 2014). Joint pain is the main symptom, leading to functional limitations and reduced quality of life (Neogi, 2013). With disease progressing, pain often becomes worse and manifests even at rest (Hawker et al., 2008). Current treatment options to relieve pain, such as NSAIDS and opioids, are insufficiently effective or fail and have substantial risks of side effects, specifically during the needed long-term treatment (Raoof et al., 2018; Conaghan et al., 2019).

OA pain may be driven by peripheral input from the affected joint because intra-articular anesthetics and total joint replacement in the majority of cases limits the pain (Creamer et al., 
1996; Arendt-Nielsen et al., 2018). OA is frequently associated with low-grade synovitis (Mathiessen and Conaghan, 2017). Locally produced inflammatory mediators such as IL- $1 \beta$, TNF, IL-6, and prostaglandin E2 directly excite and sensitize sensory neurons innervating the affected joint and cause pain (Miller et al., 2014). However, in OA patients, the severity of joint pain poorly correlates with the actual joint damage and/or synovitis (Lawrence et al., 1966; Hannan et al., 2000; O'Neill and Felson, 2018; Ostojic et al., 2019). Moreover, in $>20 \%$ of patients pain remains after total joint replacement (Wylde et al., 2011; Beswick et al., 2012). Overall, these data suggest that other mechanisms, in addition to joint damage and inflammation, contribute to the experienced OA pain.

Both preclinical and clinical evidence support the hypothesis that central mechanisms contribute to OA pain (Miller et al., 2012; Lluch et al., 2014). OA patients show signs of central sensitization. Patients with a painful knee have lower pressure pain thresholds in areas remote from the site of damage, increased temporal summation, and reduced descending inhibition of pain pathways (Woolf, 2011). In rodent models of OA, glial cell activation, including astrocytes and microglia in the spinal cord and satellite cells in the DRG, are associated with pain (Adães et al., 2017). Activated glial cells produce pro-inflammatory cytokines, chemokines, and extracellular factors such as proteases, nitric oxide, and kinins that contribute to persisting pain (Schomberg and Olson, 2012). Intriguingly, recent evidence in rodent models of neuropathic and inflammatory pain shows that immune cells modulate pain in peripheral and central pain pathways (Ji et al., 2016; Raoof et al., 2018). Activated sensory neurons produce factors including chemokine CCL2 (C-C motif ligand 2), CX3CL1 (also known as fractalkine), and CSF1 (colony stimulating factor 1), which attract immune cells to nervous tissue (Miller et al., 2012; Pinho-Ribeiro et al., 2017; Yu et al., 2020). In various chronic pain models, such as nerve-injury-induced neuropathic pain or inflammatory pain models, macrophage numbers increase in the DRG (Ghasemlou et al., 2015; Raoof et al., 2018; Yu et al., 2020). In models of OA, evidence is sparser, but examples exist that macrophages accumulate in the DRG after knee joint damage (Miller et al., 2012; Raoof et al., 2018). However, the pain regulatory function of the macrophages in OA is still poorly understood (Raoof et al., 2018). Macrophages are highly heterogeneous, and the phenotype and functions of macrophages are regulated by the surrounding microenvironment (Gordon and Plüddemann, 2017). Indeed, macrophages in nervous tissue have a unique phenotype, and neurons can drive programming of these cells. Classically activated M1-like macrophages express high levels of inducible nitric oxide synthase (iNOS) and have a pro-inflammatory profile. In contrast, alternatively activated M2-like macrophages express high levels of CD206 and have an inflammation-controlling tissue-regenerative profile but can also support tumor growth (Jablonski et al., 2015; Vitale et al., 2019). Although the precise function of these macrophages is not clear, some evidence suggests that because of different transcriptional profiles, M1- and M2-like macrophages have opposing roles in pain regulation (Raoof et al., 2018). In the current study we investigated the role of macrophages in the regulation of OA pain and whether nociceptors drive the accumulation of these macrophages.

\section{Materials and Methods}

Animals. All experiments were performed in accordance with international guidelines and approved by the experimental animal committee of University Medical Center Utrecht (DEC 2014.I.03.019) or by the local experimental animal welfare body and The Netherlands Central
Authority for Scientific Procedures on Animals (AVD115002015323 and AVD115002016490).

Adult (8-15 weeks) male and female, $L y s m^{\text {Cre }} \times$ Csflr $^{\text {LsL-DTR }}$ (catalog \#024046, The Jackson Laboratory) mice in a C57Bl/6 background $\left(\mathrm{MM}^{\mathrm{dtr}}\right)$ were used and maintained at the animal facility of Utrecht University and University Medical Center Utrecht. Heterozygous $\mathrm{Na}_{\mathrm{v}} 1.8$-Cre mice were crossed with homozygous Rosa-flox-stop DTA to generate $\mathrm{Na}_{\mathrm{v}} 1.8^{\mathrm{Cre} /+}$-DTA ${ }^{\mathrm{Loxp} /+}\left(\mathrm{Na}_{\mathrm{v}} 1.8\right.$-DTA $)$ mice that do not have $\mathrm{Na}_{\mathrm{v}} 1.8$ nociceptors from birth and littermate controls (Abrahamsen et al., 2008; Riol-Blanco et al., 2014; Udit et al., 2017; Lai et al., 2020). Experiments with $\mathrm{Na}_{\mathrm{v}} 1.8$-DTA mice were performed at University College London. Wistar rats (Charles River Laboratories), 16 weeks of age, were housed two per cage. Mice were housed in groups. All animals were kept under a 12:12 h light/dark cycle, with food and water available ad libitum. The cages contained environmental enrichments including tissue papers and shelter. Animals were acclimatized to the experimental setup for at least 1 week before the start of each experiment, and baseline measurements were at least taken three times. To minimize bias, animals were randomly assigned to different groups before the start of experiment, and experimenters were blinded for the treatments and genotypes. To determine the number of mice per group, power calculations were performed with $\mathrm{G}^{\star}$ Power version 3.1.

$O A$ pain models. Mice received an intra-articular injection of $10 \mu \mathrm{l}$ mono-iodoacetate (MIA; $10 \% \mathrm{w} / \mathrm{v}$; Sigma-Aldrich) in one knee joint (ipsilateral) under isoflurane anesthesia. The other knee joint (contralateral) received $10 \mu \mathrm{l}$ sterile saline $(0.9 \%)$. Knee joints was flexed at a $90^{\circ}$ angle, and MIA or sterile saline was injected with a 30 gauge needle (Pitcher et al., 2016).

In rats groove surgery was performed in one knee joint (ipsilateral), under isoflurane anesthesia, to induce local cartilage damage. Before groove surgery, rats received a high-fat diet (catalog \#D12492i, Research Diets) for a period of 12 weeks. Groove surgery was performed as described previously (de Visser et al., 2017). Surgery was performed in one knee joint of rats under isoflurane anesthesia to induce local cartilage damage. The knee joint cavity was opened with a small longitudinal incision through the ligamentum patellae of the knee joint. The tip of an enhanced surgical tool was bent $90^{\circ}$ at $150-180 \mu \mathrm{m}$ from the tip, to ensure the underlying subchondral bone was not damaged because the articular cartilage of a rat is $\sim 200-250 \mu \mathrm{m}$ thick. Five longitudinal grooves were applied on the weight-bearing area of the articular cartilage of both the medial and lateral femoral condyle, and three longitudinal grooves on the non-weight-bearing surface of the articular cartilage of the femoral trochlea. After the surgical procedure, all animals quickly recovered after surgery, and no wound-healing problems were observed (de Visser et al., 2017, 2018, 2019).

Pain behavioral tests. Mechanical thresholds were assessed using the von Frey test (Stoelting) with the up-and-down method to determine the $50 \%$ threshold (Chaplan et al., 1994). In short, von Frey filaments were applied for a maximum of $5 \mathrm{~s}$ to the plantar surface of the paw. After applying the first filament $(0.4 \times g)$, in case of a nonresponse, the next filament with a higher force was used. In case of a response, the next lower force filament was used. Four readings were obtained after the first change of direction.

Changes in weight bearing were evaluated using the dynamic weightbearing apparatus (BIOSEB). For mice analysis we used (1) a low-weight threshold of $0.5 \mathrm{~g}$ and (2) a high-weight threshold of $1 \mathrm{~g}$. For rat analysis we used (1) a low-weight threshold of $1 g$ and (2) a high-weight threshold of $2 g$. The following parameters were used in all the analyses: surface threshold of two cells and a minimum of five images $(0.5 \mathrm{~s})$ for stable segment detections (Prado et al., 2018). The weight bearing of the affected knee is expressed as percentage of body weight.

Depletion of monocytes and macrophages. To deplete monocytes and macrophages in vivo, $\mathrm{MM}^{\mathrm{dtr}}$ mice received a first intraperitoneal injection of $20 \mathrm{ng} / \mathrm{g}$ body-weight diphtheria toxin (DT; Sigma-Aldrich) followed by daily intraperitoneal injections of $4 \mathrm{ng} / \mathrm{g}$ body weight on all subsequent days. For local DRG macrophage depletion, each mouse received $5 \mu \mathrm{l}$ of $(5 \mathrm{ng} / \mu \mathrm{l})$ DT by daily intrathecal injections (Schreiber et al., 2013; Bourane et al., 2015). 
Monocyte isolation and in vitro differentiation into macrophages. For monocyte-derived macrophage generation, 10 million bone-marrow cells were seeded in $75 \mathrm{~cm}^{2}$ nontreated tissue culture flasks (VWR) for $7 \mathrm{~d}$ in a macrophage medium (high-glucose DMEM, catalog \#31966-021, Invitrogen) and DMEM/F12 (1:1; catalog \#31331-028, Invitrogen), supplemented with 30\% L929 cell-conditioned medium, 10\% fetal bovine serum (catalog \#10270-106, Invitrogen), 1\% Penicillin/Streptomycin (Invitrogen) and $1 \% \mathrm{~L}$-glutamine (200 mM, Thermo Fisher Scientific).

To differentiate macrophages toward M1- or M2-like macrophages, cells were stimulated with $20 \mathrm{ng} / \mathrm{ml} \mathrm{IFN} \gamma$ and $100 \mathrm{ng} / \mathrm{ml} \mathrm{LPS}$, or $20 \mathrm{ng} /$ $\mathrm{ml}$ of IL- 4 for $24 \mathrm{~h}$, respectively.

To obtain L929 cell-conditioned medium [L929-derived macrophage-colony-stimulating factor (M-CSF)], 10 million L929 cells were seeded in a $75 \mathrm{~cm}^{2}$ flask with cell culture medium supplemented with $1 \%$ nonessential amino acids (Sigma-Aldrich) for a week. L929 cells were passaged to a $162 \mathrm{~cm}^{2}$ flask with $50 \mathrm{ml}$ medium, and after a week the supernatants were collected and passed through a $0.2 \mu \mathrm{m}$ filter and stored at $-20^{\circ} \mathrm{C}$ (L929-derived M-CSF).

Adoptive transfer of macrophages. Macrophages were dissociated from the $75 \mathrm{~cm}^{2}$ nontreated tissue culture flasks (VWR) using 1\% trypsin-EDTA solution, washed in $10 \mathrm{ml}$ macrophage medium, and dissolved at a concentration of 6 million cells in $1 \mathrm{ml}$ of sterile PBS. Cells were injected intrathecally $(30,000$ cells $/ 5 \mu \mathrm{l}$ per mouse) under light isoflurane anesthesia using a 30 gauge needle as described previously (Eijkelkamp et al., 2010; Raoof et al., 2020).

Flow cytometry analysis. DRGs (L3-L5) were collected to analyze infiltrating immune cells. In brief, tissues were gently minced and digested at $37^{\circ} \mathrm{C}$ for $30 \mathrm{~min}$ with an enzyme cocktail $(1 \mathrm{mg}$ collagenase type I with $0.5 \mathrm{mg}$ trypsin in $1 \mathrm{ml}$ DMEM; Sigma-Aldrich). Cells were stained with various combinations of fluorochrome-labeled antibodies (Table 1).

Blood was collected in EDTA tubes (Greiner Bio-One) following heart puncture, and erythrocytes were lysed (red blood cell RBC lysis buffer, eBioscience) before FACS staining. Samples were acquired by LSRFortessa flow cytometer (BD Biosciences) and analyzed with FACSDiva software; counting beads were added. For all cellular analysis, we used forward scatter as a trigger to identify events.

Immunofluorescent staining and histologic preparations. Lumbar DRGs or knees were collected. DRGs were postfixed in 4\% paraformaldehyde (PFA), cryoprotected in 30\% sucrose in PBS overnight, and embedded in optimal cutting temperature compound (Sakura), and frozen at $-80^{\circ} \mathrm{C}$. Knees were fixed in $4 \%$ paraformaldehyde, decalcified in $20 \%$ EDTA, dehydrated, and embedded in paraffin wax.

For immunofluorescence, cryosections $(10 \mu \mathrm{m})$ of lumbar DRGs were stained with primary antibodies overnight at $4^{\circ} \mathrm{C}$ followed by $2 \mathrm{~h}$ incubation with fluorescent-tagged secondary antibodies (Table 1). NeuroTrace 435/455 blue fluorescent Nissl Stain (Thermo Fisher Scientific) was used for neurons. Immunostaining images were captured with a Zeiss Axio Observer microscope or an Olympus IX80 microscope, using identical exposure times for all slides within one experiment.

For histologic analysis of the knee, specimens were sagittal sectioned at $6 \mu \mathrm{m}$ and stained with safranin-O and imaged with a Zeiss Axio Lab. A1 microscope. Damage to the joint was evaluated using HistologicHistochemical Grading System score on a scale of 0-14 points (Rutgers et al., 2010). The scores were evaluated by three trained independent observers who were blinded to the groups and treatments.

iDISCO clearing procedure and light-sheet imaging. Lumbar spinal cord with DRGs attached, from adult mice, were cleared using iDISCO protocol as described previously (Renier et al., 2014). Briefly, animals were perfused with $4 \%$ PFA, the lumbar spinal cord with the spinal nerves and DRG attached were dissected, and samples were dehydrated in increasing concentrations $(20,40,60,80,100 \%)$ of methanol solutions. Samples were bleached with $5 \% \mathrm{H}_{2} \mathrm{O}_{2}$ in methanol overnight at $4^{\circ}$ $\mathrm{C}$ with shaking and rehydrated in decreasing concentrations of methanol solutions. After blocking for $48 \mathrm{~h}$ at $37^{\circ} \mathrm{C}$, samples were incubated with the primary antibodies for $48 \mathrm{~h}$ followed by incubation with a secondary antibody for another $48 \mathrm{~h}$, all at $37^{\circ} \mathrm{C}$ while rotating/shaking (Table 1). Next, samples were embedded in $1.5 \%$ agarose and dehydrated in increasing concentrations of methanol solutions. Samples were incubated overnight in 1 vol of $100 \%$ methanol/2 vol 100\% dichloromethane
Table 1. Antibodies used for flow cytometry, immune fluorescent microscopy, and iDISCO

\begin{tabular}{|c|c|c|c|c|}
\hline Target & Clone & Fluorophore & Vendor & Catalog \# \\
\hline \multicolumn{5}{|l|}{ Flow cytometry } \\
\hline CD115 & AFS98 & APC & eBioscience & 1277550 \\
\hline CD115 & AFS98 & PEeF610 & eBioscience & $61-1152-80$ \\
\hline CD11b & $\mathrm{M} 1 / 70$ & PerCPCy5.5 & BioLegend & 101227(8) \\
\hline CD11C & N418 & BV785 & BioLegend & 117336 \\
\hline CD19 & $6 \mathrm{D} 5$ & PE & BioLegend & 115508 \\
\hline CD206 & $\mathrm{C} 068 \mathrm{C} 2$ & BV650 & eBioscience & 1308615 \\
\hline CD3 & $17 A 2$ & APC & BioLegend & 100236 \\
\hline CD45 & 30-F11 & APCeF780 & eBioscience & $47-0451-82$ \\
\hline \multicolumn{5}{|c|}{ Immune fluorescent microscopy and iDISCO } \\
\hline $\mathrm{F} 4 / 80$ & BM8 & FITC & BioLegend & 123108 \\
\hline iNOS & CXNFT & APC & eBioscience & $17-5920-80$ \\
\hline Ly6C & AL-21 & BV421 & BD Bioscience & 562727 \\
\hline Ly6G & $1 \mathrm{~A} 8$ & BV785 & BioLegend & 127645 \\
\hline MHCII & M5/114.15.2 & PerCP & BioLegend & 107624 \\
\hline $\mathrm{F} 4 / 80$ & C1:A3-1 rat & None & Cedarlane & CL8940AP \\
\hline$\beta 3$-Tubulin & Polyclonal rabbit & None & Abcam & ab18207 \\
\hline CD68 (anti-rat) & ED1 mouse & None & BIO-RAD & MCA341GA \\
\hline Iba1 & Polyclonal rabbit & None & WAKO & 019-19741 \\
\hline NF200 & Polyclonal rabbit & None & Sigma & $\mathrm{N} 4142$ \\
\hline Peripherin & Mouse & None & Sigma & P5117 \\
\hline Anti-mouse & Donkey & AF488 & LifeTech & A21202 \\
\hline Anti-rabbit & Donkey & AF568 & LifeTech & A10042 \\
\hline Anti-rat & Goat & AF647 & LifeTech & A21247 \\
\hline
\end{tabular}

(DCM) anhydrous, washed with 100\% DCM for $1 \mathrm{~h}$, and incubated in $100 \%$ dibenzyl ether for at least $1 \mathrm{~d}$ before imaging. Samples were imaged with an Ultramicroscope II (LaVision BioTec) light-sheet microscope equipped with Imspector (version 5.0285.0) software (LaVision BioTec). The microscope consists of an Olympus MVX10 Zoom Body (0.63-6.3×) equipped with an Olympus MVPLAPO $2 \times$ objective lens, which includes dipping cap correction optics (catalog \#LV OM DCC20) with a working distance of $5.7 \mathrm{~mm}$. The effective magnification for the images was $1.36 \times$ (zoombody ${ }^{*}$ objective + dipping lens $=0.63 \times * 2.152 \times$ ). Images were taken with a Neo sCMOS camera (Andor; $2560 \times 2160$ pixels, pixel size $6.5 \times 6.5$ um2). Samples were scanned with a sheet numerical aperture of 0.148348 (results in a sheet $5 \mu \mathrm{m}$ thick) and a step size of $2.5 \mu \mathrm{m}$, using the horizontal focusing light-sheet scanning method with the optimal number of steps and using the contrast blending algorithm. The following laser filter combinations were used: Coherent OBIS 561-100 LS Laser with 615/40 filter and Coherent OBIS 647-120 LX with 676/29 filter.

Statistical analysis. All data are presented as mean \pm SEM and were analyzed with GraphPad Prism software version 8.3. For comparison between two groups, an unpaired two-tailed $t$ test was used. For comparison among more than two groups, a one-way or two-way ANOVA, or an appropriate repeated-measures ANOVA, followed by post hoc analysis was used with appropriate corrections for multiple testing (for the outcome of statistical tests, see below, Results). For repeated-measures ANOVA, $F$ values and degrees of freedom of Time $\times$ Treatment interactions are provided. The statistical and post hoc analyses that were used are indicated in each figure legend. A $p$ value $<0.05$ was considered statistically significant, and each significance is indicated by ${ }^{*} p<0.05,{ }^{* *} p<0.01,{ }^{* *} p<0.001$.

Data availability. All data are available in the article or in supplementary materials. Raw data and materials are available on reasonable request. Some materials used in this manuscript are subject to a material transfer agreement.

\section{Results}

\section{Macrophages accumulate in the DRG during osteoarthritis} pain

Joint damage was induced by a unilateral intra-articular injection of MIA in mice (Pitcher et al., 2016). MIA injection induced joint pathology that was present at week 1 and persisted for at least 4 

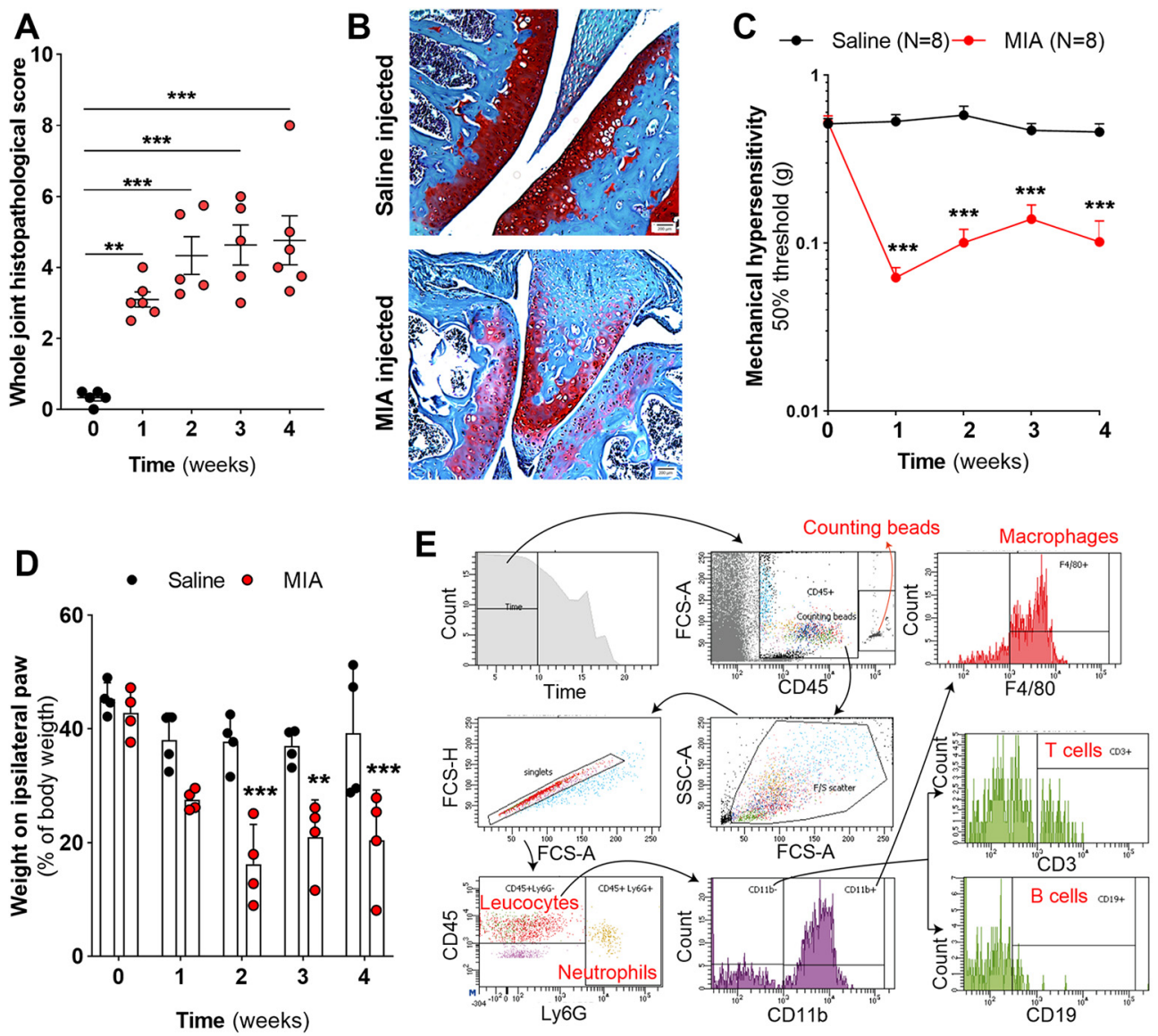

$\mathbf{F}$

G
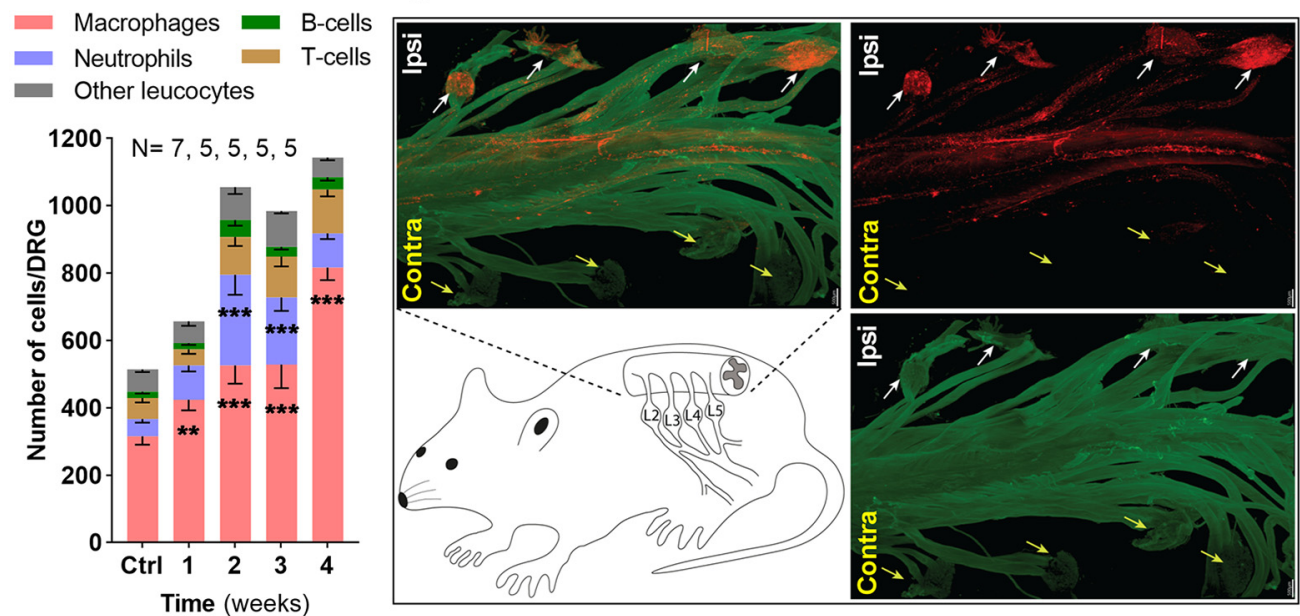

Figure 1. Macrophages infiltrate the DRG in MIA-induced OA pain. A, Quantification of histopathological changes in the knee joints over 4 weeks after intra-articular MIA injection in mice. Knee joints were dissected for histology at indicated time points and scored according to the Histologic-Histochemical Grading System. One-way ANOVA with Dunnett's post hoc. B, Exemplar image of mice knee joints at week 3 after intra-articular injection of MIA or saline. The knee joints were stained with safranin-0. The femur is on the left side, and the tibia is at the right. Left, Image shows the normal cartilage structure (red staining) of the joint after saline injection. Right, Image shows MIA-induced knee joint lesion that was observed in the joint of the MIA-injected mice. Scale bar, $200 \mu$ м. C, Course of mechanical hyperalgesia after injection of MIA in the ipsilateral or saline in the contralateral knee. Mechanical hyperalgesia was followed over time using Von Frey. Two-way ANOVA with Sidak's post hoc. D, Course of weight distribution determined after intra-articular injection of MIA or saline in the contralateral knee using dynamic weight-bearing apparatus. Two-way repeated-measures ANOVA with Sidak's post hoc. $\boldsymbol{E}$, Gating strategy to identify the immune cells (as displayed in $\boldsymbol{F}$ ) in the lumbar DRG (L3-L5) after MIA injection. A time gate unified the acquisition analysis, followed by a rough separation of events based on CD45 expression but excluding the counting beads. Cells were further gated by FCS/SSC (to identify the size of each cell), single cells, and CD45 and Ly6G expression before analysis of CD11b and F4/80. CD3 and CD19 cells were identified from the CD11b-negative cells. $F$, Lumbar ipsilateral DRG (L3-L5), from male and female mice, containing the sensory neurons innervating the knees that received MIA were isolated at each time point. The absolute number of CD45+ cells, classified to subsets, is divided by the total DRGs analyzed per mouse. The control group consists of mice DRG that received saline and isolated at the different time points (1, 2, 3, and 4 weeks). Two-way ANOVA with Dunnett's post hoc. G, Light-sheet rendering of lumbar spinal cord with the spinal nerves and DRG attached of mice injected at one knee intra-articular with MIA (ipsilateral), and the other knee with saline (contralateral). Neurons are stained with neurofilament $\mathrm{M}$ (green) and macrophages with F4/80 (red). White arrows indicate the ipsilateral DRG, and yellow arrows indicate the contralateral DRG containing neurons innervating the saline-injected knee (Movie 1). Scale bar, $500 \mu \mathrm{m} .{ }^{* *} p<0.01 ;{ }^{* * *} p<0.001$. 
weeks $\left(F_{(4,22)}=13.93, p<0.001\right.$; Fig. $\left.1 A, B\right)$. Intra-articular MIA injection-induced pain-like behavior such as mechanical hypersensitivity $\left(F_{(4,56)}=9.053, p<0.001\right.$; Fig. $\left.1 C\right)$ and a reduction of weight bearing $\left(F_{(4,24)}=2.876, p<0.05\right.$; Fig. $\left.1 D\right)$ of the affected leg that persisted for at least 4 weeks.

To identify whether the persisting pain was associated with immune cell infiltration, the lumbar (L3-L5) DRG containing the somata of sensory neurons that innervate the knee joint were analyzed using flow cytometry (Fig. $1 E$, gating strategy). The number of $\mathrm{CD} 1 \mathrm{~b}^{+} \mathrm{F} 4 / 80^{+}$macrophages was increased at 1 week after intra-articular MIA injection and peaked at 3-4 weeks $\left(F_{(16,128)}=10.98, p<0.001\right.$; Fig. $\left.1 F\right) . \mathrm{CD}_{11 b^{-}} \mathrm{CD}^{+} \mathrm{T}$ cell and

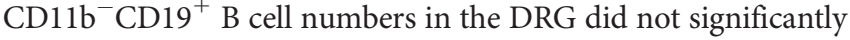
change over time (Fig. 1F). In contrast, the number of $\mathrm{CD}_{4}{ }^{+} \mathrm{Ly}_{6 \mathrm{G}}{ }^{+}$neutrophils increased at weeks 2 and 3 after MIA injection but returned to baseline numbers 4 weeks after MIA injection (Fig. 1F). To further identify where the macrophages were localized within the tissue, we performed iDISCO tissue clearing followed by staining of the lumbar spinal cord with the spinal nerves and DRG attached. Macrophages are clearly present throughout the ipsilateral but not contralateral DRG and dorsal horn of the spinal cord at 3 weeks after intra-articular MIA injection (ipsilateral) or saline in the contralateral knee joint. (Fig. 1G; Movie 1).

To test whether macrophage accumulation in the DRG is a generic phenomenon that occurs also when OA is induced differently and in a different species, we used the tibia-femoral groove model in obese rats as described before (de Visser et al., 2019). The groove model in obese rats combines systemic metabolic alterations with local cartilage damage and results in mild knee joint degeneration without permanent joint instability and only limited joint inflammation (de Visser et al., 2019). At 12 weeks after groove surgery, histologic OA scores were significantly increased $(t=5.580, \mathrm{df}=8, p=0.0005$; Fig. $2 A, B)$. Groove surgery significantly decreased mechanical withdrawal thresholds $\left(F_{(1,10)}=12.63, p=0.0052\right.$; Fig. $\left.2 C\right)$ and weight bearing of the affected leg $(t=2.895, \mathrm{df}=10, p=0.016$; Fig. $2 D)$ at 12 weeks compared with the sham-operated controls. Macrophages either stained for CD68 or Ibal in the lumbar DRGs innervating the grooved OA knees were significantly enhanced compared with DRGs related to the nongrooved contralateral knees at 12 weeks after surgery (CD68: $t=3.494, \mathrm{df}=4, p=0.025$; Iba1; $t=3.316$, $\mathrm{df}=5$; Fig. 2E)

\section{Macrophages maintain osteoarthritis pain}

To address the function of DRG infiltrating macrophages in OA pain, we selectively depleted monocytes and macrophages 3 weeks after intra-articular MIA injection. Cells were depleted by injection of DT in mice that specifically express the diphtheria toxin receptor in monocytes and macrophages $\left(\right.$ Lysm $^{\text {cre }}$ x Csfr1Stop-DTR mice; $\left.\mathrm{MM}^{\mathrm{dtr}}\right)$. Daily intraperitoneal injections of DT reduced the number of $\mathrm{F} 4 / 80^{+}$macrophages in the $\mathrm{DRG}\left(F_{(4,69)}=\right.$ 8.242, $p<0.001$; Fig. $3 A)$ as well as $\mathrm{CD} 115^{+}$blood circulating monocytes (Fig. $3 B$ ). The number of other immune cells including

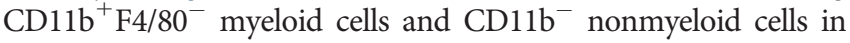
the DRG did not change $\left(F_{(2,38)}=8.689, p=0.0008\right.$; Fig. $\left.3 A\right)$. Intraperitoneal DT administration to $\mathrm{MM}^{\mathrm{dtr}}$ mice completely resolved the ongoing MIA-induced mechanical hyperalgesia $\left(F_{(21,168)}=4.113, p<0.001\right.$; Fig. $\left.3 C\right)$ and resolved the deficits in weight bearing of the affected knee $\left(F_{(5,60)}=6.957, p<0.0001\right.$; Fig. $3 D$ ). In control mice, sensitivity to mechanical stimuli was not affected by intraperitoneal DT administration (Fig. 3C,D).

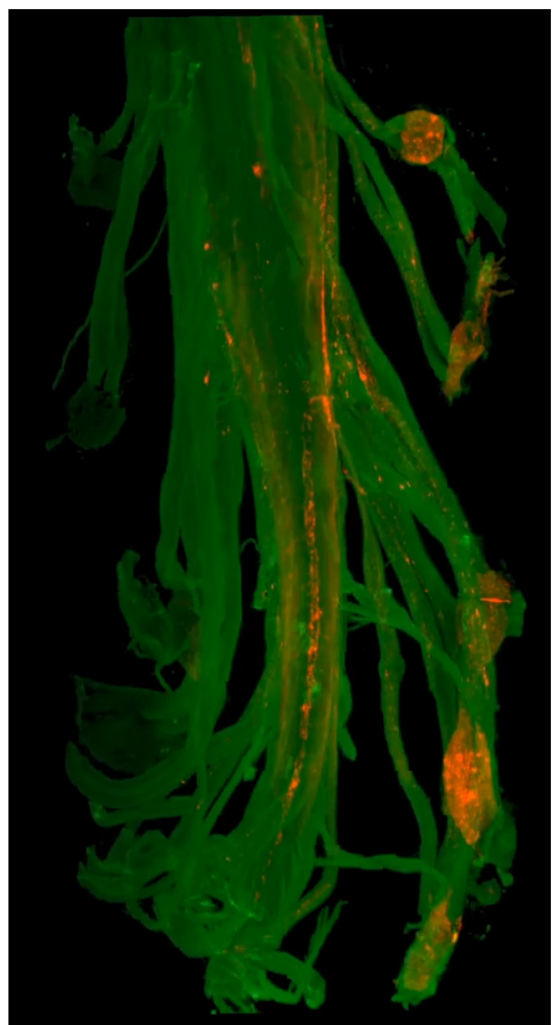

Movie 1. Macrophages infiltrate DRG in MIA-induced OA pain. Light-sheet 3D rendering of lumbar spinal cord with the spinal nerves and DRG attached of a mouse injected at one knee intra-articularly with MIA (ipsilateral) and the other knee with saline (contralateral). Neurons are stained with neurofilament $M$ (green) and macrophages with F4/80 (red). Scale bar, $500 \mu \mathrm{m}$. [View online]

To address whether local depletion of DRG macrophages is sufficient to resolve OA-induced persisting pain behaviors, DT was intrathecally injected in $\mathrm{MM}^{\mathrm{dtr}}$ mice. Intrathecal DT injection selectively depleted macrophages from the DRG without affecting blood circulating monocytes and other $\mathrm{CD} 45^{+} \mathrm{F} 4 / 80^{-}$ leukocytes in the DRG (Fig. $3 A, B$ ). Importantly, local depletion of macrophages in the DRG completely resolved established persistent MIA-induced mechanical hyperalgesia $\left(F_{(21,262)}=4.539\right.$, $p<0.001$; Fig. $3 E$ ) and reduced weight bearing of the affected knee $\left(F_{(5,55)}=2.685, p=0.0305\right.$; Fig. $\left.3 F\right)$. In both male and female mice, depletion of monocytes/macrophages reduced pain to the same extent after systemic DT administration $\left(F_{(7,42)}=\right.$ $0.3832, p=0.91$; Fig. $3 C$ ) or intrathecal DT administration $\left(F_{(7,47)}=0.4714, p=0.85\right.$; Fig. $\left.3 E\right)$. Overall, these data show that macrophages infiltrating the DRG are responsible for maintaining OA pain.

\section{DRG macrophage recruitment and polarization is independent of $\mathrm{Na}_{\mathrm{v}} 1.8$ nociceptors}

We next phenotypically analyzed DRG macrophages using M1 and M2 markers. Expression of iNOS (an M1 macrophage marker) significantly increased in DRG infiltrating macrophages from week 1 after MIA injection and remained elevated until at least 4 weeks $\left(F_{(4,31)}=8.213, p=0.0001\right.$; Fig. $\left.4 A\right)$. In contrast, expression of CD206 (an M2 macrophage marker) remained similar (or even tended to be decreased) in MIA-injected mice compared with control mice during the 4 weeks $\left(F_{(4,31)}=1.314\right.$, $p=0.2866$; Fig. $4 B$ ). Thus, during OA pain, macrophages acquire an M1-like phenotype. To assess whether sensory neurons in the 
A week $12 \quad$ B
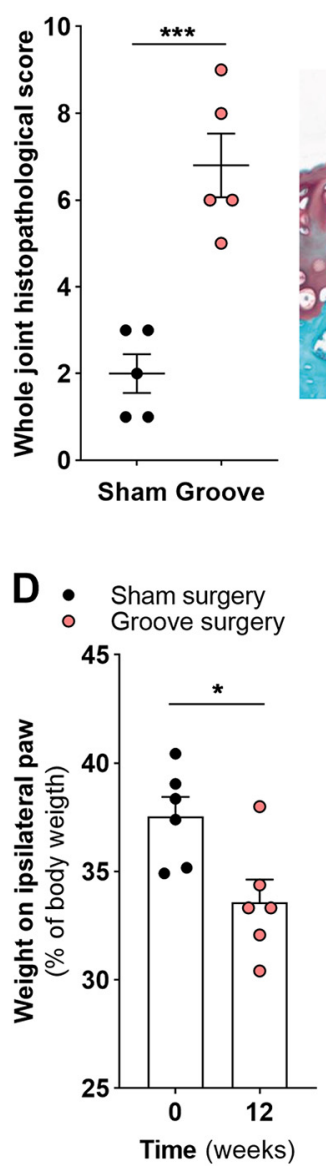

B

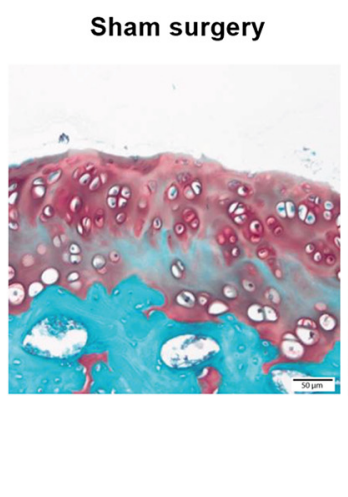

E

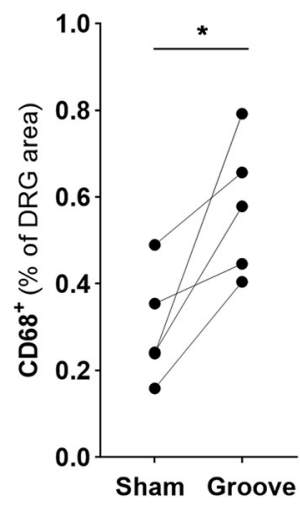

Groove surgery

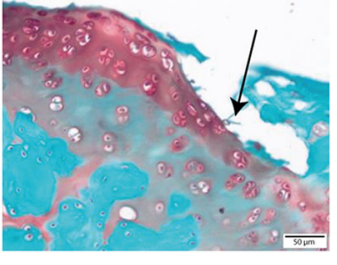

C Sham surgery

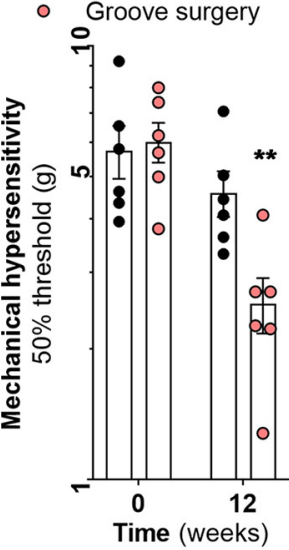

Figure 2. Groove surgery induced OA-like pain and macrophage accumulation in the DRG. $A$, Quantification of histopathological changes in the obese rat knee joints 12 weeks after groove or sham surgery. The cartilage degeneration is scored according to the Histologic-Histochemical Grading System. Unpaired two-tailed $t$ tests. $\boldsymbol{B}$, Representative picture of histopathological changes in the rat knee joints 12 weeks after groove or sham surgery. The knee joints were stained with safranin-0. The arrow indicates the cartilage degeneration induced by groove surgery. Scale bar, $50 \mu$ m. C, Mechanical hyperalgesia at the hindpaw after groove (ipsilateral) or sham (contralateral) operation in rat knee joints before and 12 weeks after surgery. Two-way ANOVA with Sidak's post hoc. D, Paw weight distribution of the affected ipsilateral leg was evaluated before and 12 weeks after groove surgery in rat knee joints using dynamic weight bearing. Unpaired two-tailed $t$ tests. $\boldsymbol{E}$, Quantification of macrophages in infiltrated lumbar (L3-L5) DRG containing the sensory neurons innervating the knees at 12 weeks after groove (ipsilateral) or sham operation contralateral by assessment of $\mathrm{CD}_{6} 8^{+}$and $\mathrm{Iba} 1^{+}$immunostaining. Paired two-tailed $t$ tests. Exemplar immunofluorescent microscopy images of lba ${ }^{+}$macrophages (green) in the lumbar (L3-L5) DRG in rats at 12 weeks after groove or sham operations. Neurons were visualized with neurotrace Nissl stain (red). ${ }^{*} p<0.05 ;{ }^{* *} p<0.01 ;{ }^{* * *} p<0.001$.

DRG drive this M1 skewing of macrophages, we cocultured bone-marrow-derived macrophages with isolated sensory neurons that innervated the affected joint (ipsilateral) and those innervating the healthy joint (contralateral) 1 week after MIA injection. Macrophages cultured for $24 \mathrm{~h}$ with sensory neurons innervating the ipsilateral knee expressed more iNOS than macrophages cultured with sensory neurons innervating the contralateral knee joint $\left(F_{(2,13)}=124.2, p<0.001\right.$; Fig. $\left.4 C\right)$. Expression of the M2 macrophage marker CD206 did not change significantly $\left(\mathrm{F}_{(2,13)}=1.058, p=0.3753\right.$; Fig. $\left.4 D\right)$. Thus, sensory neurons from osteoarthritis mice program macrophages into an M1like phenotype.

$\mathrm{Na}_{\mathrm{v}} 1.8$ Nociceptors are required for development of inflammatory but not neuropathic pain (Abrahamsen et al., 2008). To test whether $\mathrm{Na}_{\mathrm{v}} 1.8$ nociceptors drive the accumulation and programming of DRG macrophages in OA pain and the mechanical hypersensitivity, we used $\mathrm{Na}_{\mathrm{v}} 1.8$-DTA mice in which $\mathrm{Na}_{\mathrm{v}} 1.8$ nociceptors are ablated from birth by expression of diphtheria toxin $\mathrm{A}$ in $\mathrm{Na}_{\mathrm{v}} 1.8$ neurons (Abrahamsen et al., 2008; Riol-Blanco et al., 2014; Udit et al., 2017; Lai et al., 2020). In $\mathrm{Na}_{\mathrm{v}} 1.8$-DTA mice $85 \%$ of small peripherin ${ }^{+}$neurons are lost, but large-diameter $\mathrm{NF}_{200}{ }^{+}$are still intact (Abrahamsen et al., 2008; Riol-
Blanco et al., 2014; Udit et al., 2017; Lai et al., 2020). Peripherin and NF200 staining confirmed deletion of predominantly smalldiameter neurons (Fig. 4E). MIA-induced persistent pain in $\mathrm{Na}_{\mathrm{v}} 1.8$-DTA mice was indistinguishable compared with wildtype mice for either mechanical sensitivity of the ipsilateral hindpaw $\left(F_{(2,31)}=0.9232, p=0,4079\right.$; Fig. $\left.4 F\right)$ or weight bearing of the affected leg $\left(F_{(2,23)}=1.836, p=0.1820\right.$; Fig. $\left.4 G\right)$. Moreover, the number and phenotype of DRG infiltrating macrophages were similar between $\mathrm{Na}_{\mathrm{v}} 1.8$-DTA and wild-type mice $(H$, $F_{(10,60)}=2.788, p=0.007 ; I, F_{(2,29)}=0.1167, p=0.8903 ; J, F_{(2,29)}=$ $0.3220, p=0.73$; Fig. $4 H-J)$. No significant differences were

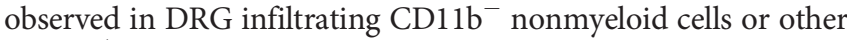

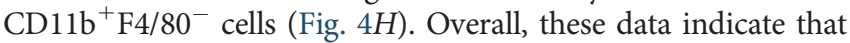
$\mathrm{Na}_{\mathrm{v}} 1.8$ nociceptors do not mediate OA pain. Moreover, sensory neurons, but not $\mathrm{Na}_{\mathrm{v}} 1.8$ nociceptors, control macrophage recruitment and $\mathrm{M} 1$ differentiation of DRG macrophages during MIA-induced OA pain.

Macrophages induce or resolve pain depending on phenotype

Macrophages release different types of cytokines depending on phenotype. M1-like macrophages release inflammatory cytokines 

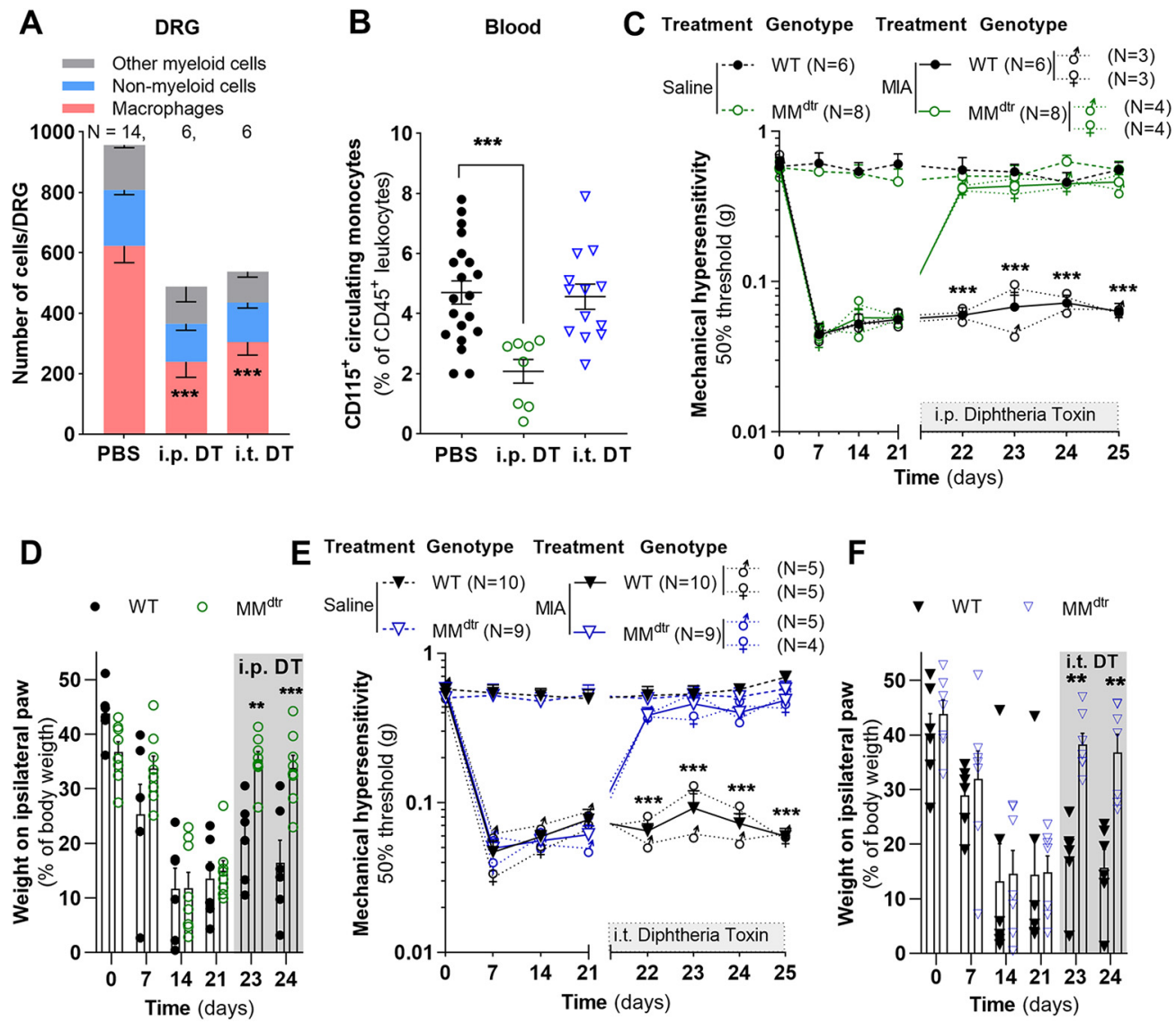

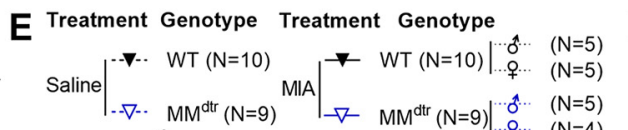

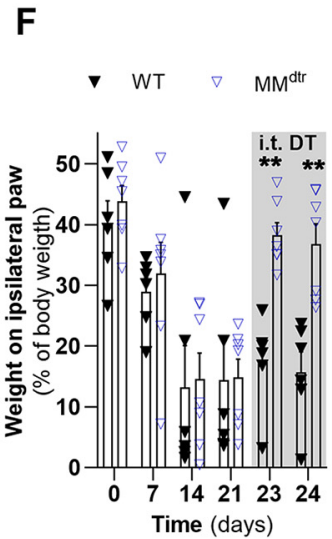

Figure 3. DRG infiltrating macrophages maintain osteoarthritis pain. $\boldsymbol{A}, \boldsymbol{B}$, Flow cytometry analysis of single-cell suspension of DRG and blood isolated from MM ${ }^{\mathrm{dtr}}$ mice treated with DT, intraperitoneal or intrathecal, to validate monocyte and macrophage depletion at week 4 after MIA injection. $\boldsymbol{A}$, Number of F4/80 ${ }^{+}$macrophages, nonmyeloid cells $\left(C D 45^{+}\left(D 11 b^{-}\right)\right.$, and other myeloid cells $\left(C D 11 b^{+} F 4 / 80^{-}\right)$in the DRG of $M^{\text {dtr }}$ mice after intraperitoneal and intrathecal injections of DT. Two-way ANOVA with Dunnett's post hoc. $B$, Flow cytometry analysis of $C D 45^{+} \mathrm{CD}_{11 b^{+}} \mathrm{CD} 115^{+}$monocytes in blood after intraperitoneal and intrathecal injections of DT in MM ${ }^{\text {dtr }}$ mice. One-way ANOVA with Dunnett's post hoc. C, Course of mechanical hyperalgesia in WT versus MM $^{\text {dtr }}$ mice, in female and male mice, after intra-articular injection of MIA in the ipsilateral knee and saline in the contralateral knee. Monocytes/macrophages were systemically depleted by daily intraperitoneal injections of DT starting at day 21. Two-way ANOVA with Tukey's post hoc comparing $M M^{\text {dtr }}$ to WT in each time point. Statistical analyses using a repeated-measures ANOVA indicated that the course of mechanical hyperalgesia was not significantly different between males and females. $\boldsymbol{D}$, Weight distribution of the ipsilateral hindpaws at indicated time points in WT versus MM ${ }^{\text {dtr }}$ mice after intra-articular injection of MIA in the left hindpaw and saline in the right hindpaw. Mice were treated with daily intraperitoneal injection of DT starting at day 21 to deplete monocytes/macrophages. Two-way ANOVA with Sidak's post hoc. $\boldsymbol{E}$, Course of mechanical hyperalgesia in WT versus MM $^{\mathrm{dtr}}$ mice, in female and male mice, after intra-articular injection of MIA in the ipsilateral knee and saline in the contralateral knee. Mice received daily intrathecal injections of DT starting at day 21 to deplete macrophages in the lumbar DRG. Two-way ANOVA with Tukey's post hoc comparing $\mathrm{MM}^{\mathrm{dtr}}$ to WT in each time point. Statistical analyses using a repeated-measures ANOVA indicated that the course of mechanical hyperalgesia was not significantly different between males and females. $\boldsymbol{F}$, Weight distribution of the ipsilateral hindpaws at indicated time points in WT versus MM $^{\text {dtr }}$ mice after intra-articular injection of MIA in the ipsilateral knee and saline in the contralateral knee. Mice received daily intrathecal injection of DT starting at day 21 to deplete macrophages in the lumbar DRG. Two-way ANOVA with Sidak's post hoc. i.p., Intraperitoneal; i.t., intrathecal. ${ }^{* *} p<0.01 ;{ }^{* * *} p<0.001$.

such as IL-1 $\beta$ and TNF, which may promote pain, whereas M2 macrophages release more anti-inflammatory cytokines such as IL10, which can resolve pain (Martinez and Gordon, 2014; Atri et al., 2018; Saqib et al., 2018).

To address whether the pain regulatory role of macrophages in the DRG is determined by phenotype, we programmed macrophages in vitro into an M1-like phenotype before injecting them close to the DRG and spinal cord by intrathecal injection in naive mice. Macrophages stimulated with $20 \mathrm{ng} / \mathrm{ml}$ IFN $\gamma$ and $100 \mathrm{ng} / \mathrm{ml}$ LPS for $24 \mathrm{~h}$ strongly upregulated the M1 marker $\operatorname{iNOS}\left(F_{(3,18)}=491.7, p<0.001\right.$; Fig. $\left.5 A\right)$. In contrast to nonprogrammed M0 macrophages, intrathecal injection of M1-like macrophages in naive mice induced transient mechanical hypersensitivity at the hindpaws that resolved within $4 \mathrm{~d}$, indicating the M1-like phenotype of macrophages governs a pain-promoting role $\left(F_{(7,56)}=3.824, p=0.0018\right.$; Fig. $\left.5 B\right)$. The effect of intrathecal M0 and M1 injections was similar in both males and females $\left(\mathrm{M} 0, F_{(5,15)}=1.738, p=0.1866 ; \mathrm{M} 1, F_{(5,15)}=1.291, p=\right.$ 0.3191 ). At $6 \mathrm{~h}$ and $24 \mathrm{~h}$ after intrathecal injection of either M0 and M1 macrophages, there was a visual increase in F4/80 immunostaining in the DRG, indicating macrophages accumulate in the DRG (Fig. 5C).

M2 macrophages may inhibit the pro-inflammatory M1 macrophages and as such could dampen OA pain. To test whether M2 macrophages modulate macrophage M1 polarization, we cocultured M1 macrophages with mCherry2-expressing M2 macrophages to enable analyses of each population separately. Macrophages stimulated with $20 \mathrm{ng} / \mathrm{ml} \mathrm{IL}-4$ for $24 \mathrm{~h}$ had increased expression of M2 marker CD206 compared with unstimulated M0 macrophages $\left(F_{(3,18)}=226.8, p<0.001\right.$; Fig. $\left.5 D\right)$. Coculture of M1 macrophages with mCherry2-expressing M2 macrophages reduced the iNOS expression in the M1 macrophages compared with nontreated M1 macrophages (Fig. 5A). M2 macrophages did not affect CD206 expression in M1 macrophages (Fig. 5D). 

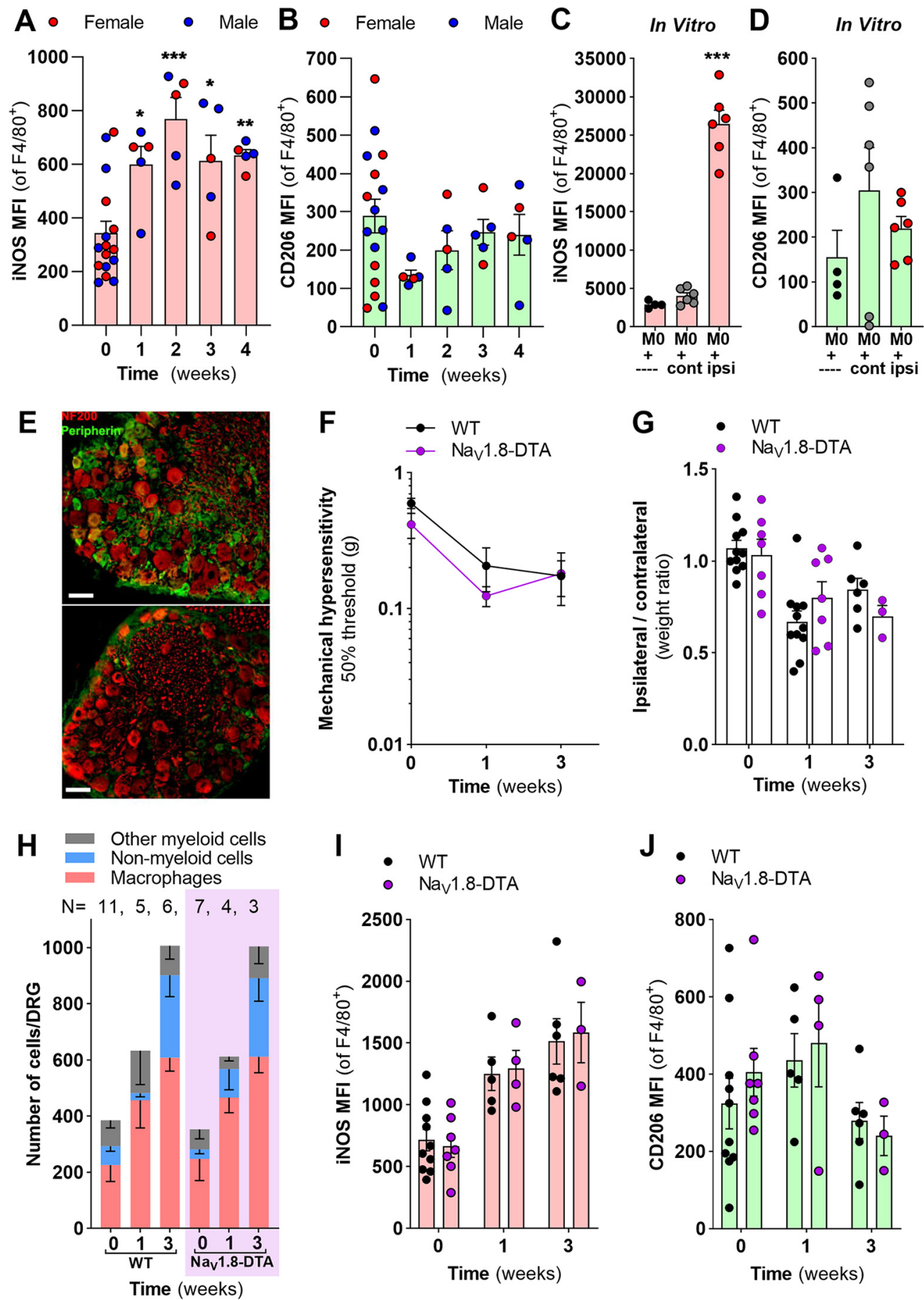

Figure 4. DRG infiltrating macrophages acquire an M1-like phenotype independent of nociceptors. $\boldsymbol{A}, \boldsymbol{B}$, Median fluorescence intensity (MFI) of $(\boldsymbol{A})$ iNOS and $(\boldsymbol{B}) \mathrm{CD} 06$ of the $\mathrm{F} 4 / 80^{+}$macrophage population in the DRG of mice at the indicated time points after intra-articular injection of MIA. One-way ANOVA with Dunnett's post hoc comparing MFI in indicated time point. C, $\mathbf{D}$, MFI of $(\boldsymbol{A})$ iNOS and $(\boldsymbol{B})$ CD206 of bone-marrow-derived macrophages in vitro cocultured for $24 \mathrm{~h}$ with isolated sensory neurons that innervated the MIA-injected joint (ipsilateral) or healthy joint (contralateral) 1 week after MIA injection. One-way ANOVA with Dunnett's post hoc. $\boldsymbol{E}$, Representative immunofluorescent microscopy images of peripherin (green; small-diameter neurons) and NF200 (red; large-diameter neurons) in littermate controls (above) and Nav1.8-DTA mice (below). $\boldsymbol{F}$, Course of mechanical hyperalgesia after intra-articular injection of MIA in wild-type (week 0/1, $n=7$; week $3, n=6$ ). versus $\mathrm{Na}_{\mathrm{v}} 1.8$-DTA mice (week 0/1, $n=7$; week $3, n=3$ ). Two-way ANOVA with Sidak's post hoc. $\mathbf{G}$, Weight distribution of WT versus Na 1 18-DTA mice before and at 1 and 3 weeks after intra-articular injection of MIA using static weight-bearing apparatus. Two-way ANOVA with Sidak's post hoc. $\boldsymbol{H}_{\text {, Absolute number of CD45 }}^{+}$leukocytes classified to subset per lumbar DRG of WT compared with Na 1.8-DTA mice (purple background) at indicated time points after intra-articular MIA injection. Two-way ANOVA with Dunnett's post hoc,

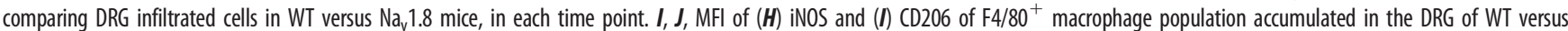
$\mathrm{Na}_{v} 1.8$-DTA before and at 1 and 3 weeks after intra-articular injection of MIA. Two-way ANOVA with Sidak's post hoc. ${ }^{*} p<0.05 ;{ }^{* *} p<0.01 ;{ }^{* * *} p<0.001$.

To verify whether M2 macrophages also inhibit M1 macrophages in vivo, we injected 30,000 M2 macrophages intrathecally at day 21 during established MIA-induced pain. Injection of M2 macrophages reduced iNOS expression of the total $\mathrm{F} 4 / 80^{+}$ macrophage population in the DRG compared with mice that received M0 macrophages $\left(F_{(1,20)}=8.536, p=0.0084\right.$; Fig. $\left.5 E\right)$. Intrathecal injection of M2 macrophages resolved the persistent MIA-induced mechanical hypersensitivity (Fig. $5 F ; F_{(30,160)}=$ 

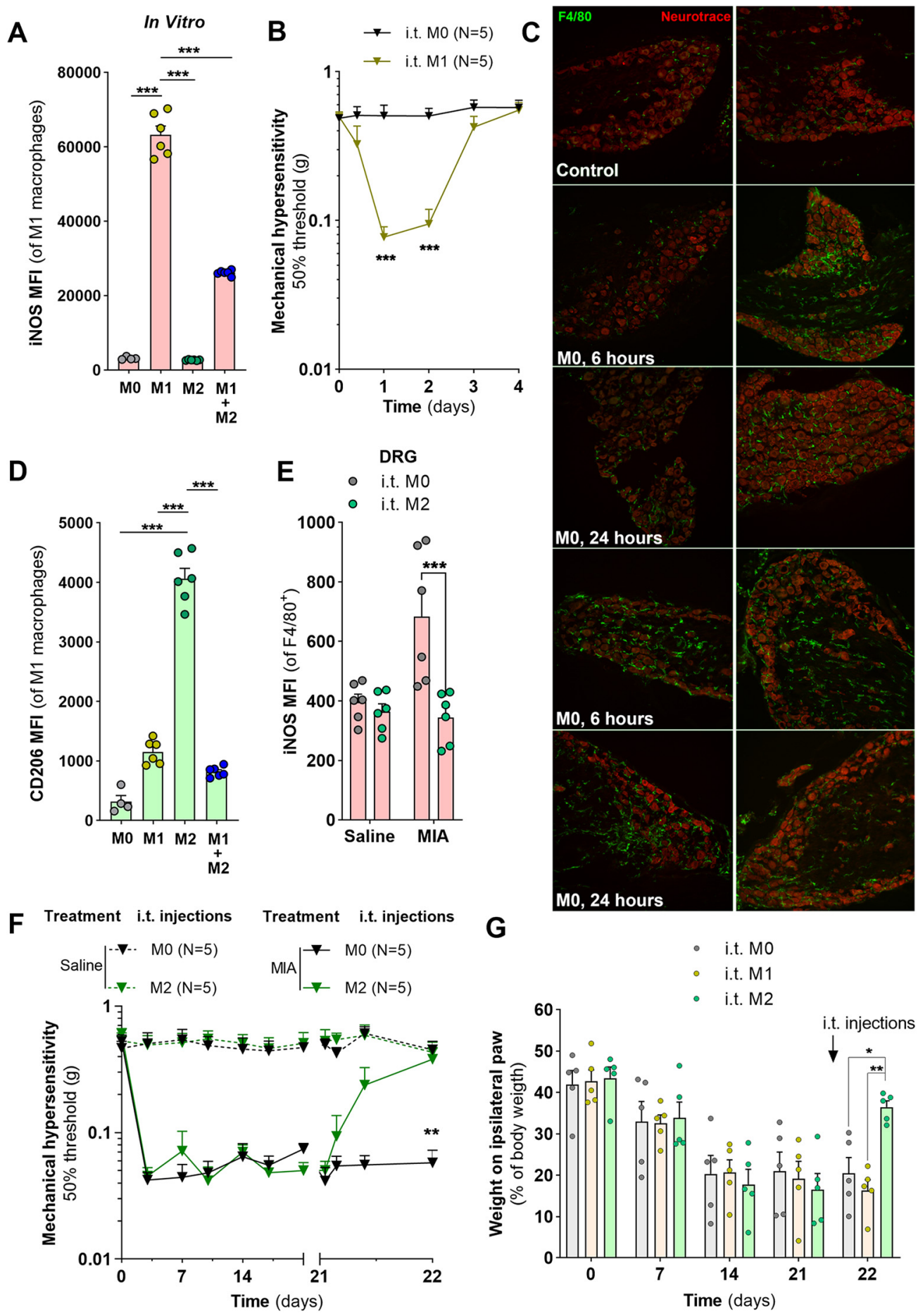

Figure 5. The M1 phenotype of DRG macrophages regulates the pain-promoting function. $A$, Median fluorescence intensity (MFI) of iNOS in macrophages that were differentiated in vitro into an M1-like phenotype or M2-like phenotype, and M1 macrophages cocultured for $24 \mathrm{~h}$ with mCherry2 expressing M2-like macrophages. Expression of iNOS was determined after gating out the mCherry2-positive macrophages. One-way ANOVA with Tukey's post hoc. B, Course of mechanical hyperalgesia in naive mice (males and females) injected intrathecally with 30,000 M0 or M1-like macrophages. Two-way ANOVA with Sidak's post hoc comparing mice that received M0 to M1 injected in each time point. C, Exemplar pictures of F4/80 staining (green) and neuronal staining (red) of untreated mice and mice (6 and $24 \mathrm{~h}$ ) after intrathecal injection with M0 or M1 macrophages. Representative images shown for each mouse. D, MFI of CD206 in macrophages that were differentiated in vitro into an M1-like phenotype or M2-like phenotype, and M1 macrophages cocultured for $24 \mathrm{~h}$ with mCherry2 expressing M2-like macrophages. Expression of CD206 was determined after gating out the mCherry2-positive macrophages. One-way ANOVA with Tukey's post hoc. $E$, iNOS Median fluorescence intensity (MFI) of F4/80 ${ }^{+}$macrophage population in the DRG of mice $24 \mathrm{~h}$ after intrathecal injection of M2-like macrophages. All animals received intra-articular injection of MIA or saline at day 0 and a single intrathecal injection of macrophages at day 21. DRGs were isolated at day 22. Two-way ANOVA with Sidak's post hoc. $\boldsymbol{F}$, Course of mechanical hyperalgesia after intra-articular injection of MIA in the left hindpaw and saline in the right hindpaw. Mice were injected intrathecally with M0 macrophages or M2-like macrophages at day 21. Arrow indicates the moment of intrathecal injection of macrophages. Two-way ANOVA with Sidak's post hoc comparing M0 to M2 injection in saline- and MIA-treated mice in each time point. Each group consisted of two males and three females. G, Weight distribution of ipsilateral hindpaws during the course of MIA-induced $\mathrm{OA}$ in mice treated with intrathecal injection of $\mathrm{MO}$ macrophages, M1-like macrophages, or M2-like macrophages at day 21. Arrow indicates the moment of intrathecal injection of macrophages. Two-way ANOVA with Sidak's post hoc. i.t., Intrathecal. ${ }^{*} p<0.05$; ${ }^{* *} p<0.01 ;{ }^{* *} p<0.001$. 
A
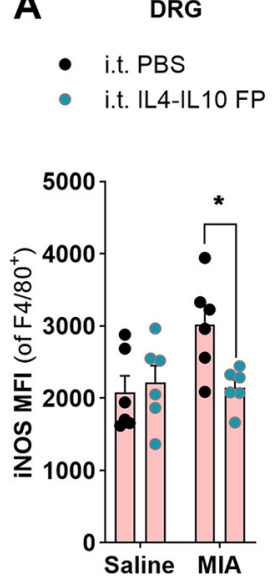

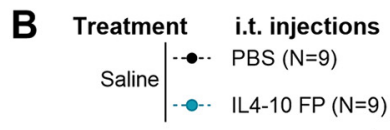

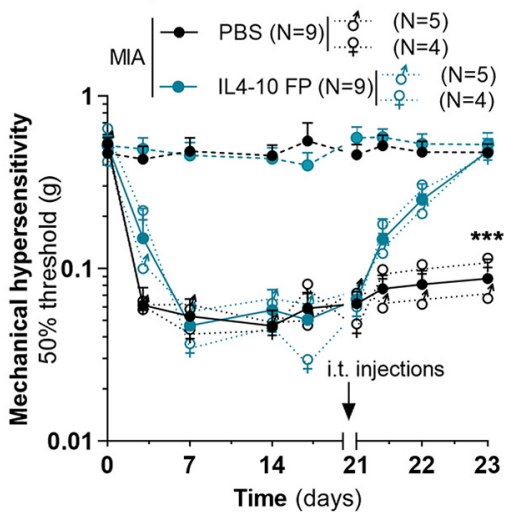

C

- i.t. PBS

- i.t. IL4-10 FP

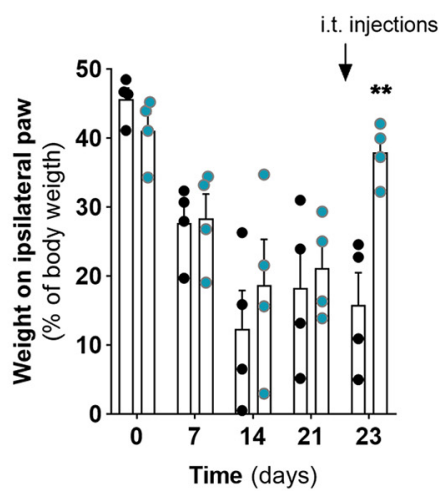

Figure 6. Inhibiting inflammatory DRG macrophages with a fusion protein of IL4-10 resolves OA pain. $A$, iNOS Median fluorescence intensity (MFI) of F4/80 ${ }^{+}$macrophages in the DRG of mice $48 \mathrm{~h}$ after intrathecal injection of IL4-10 FP. All animals received an intra-articular injection of MIA or saline at day 0, intrathecal injections were done at day 21, and DRGs were isolated at day 23. Two-way ANOVA with Sidak's post hoc. B, Course of mechanical hyperalgesia after intra-articular injection of MIA in the left hindpaw and saline in the right hindpaw. Mice were intrathecally injected with IL4-10 FP or PBS. Two-way ANOVA with Sidak's post hoc comparing PBS to IL4-10 FP in saline- and MIA-treated mice in each time point. Statistical analyses using a repeated-measures ANOVA indicated that the course of mechanical hyperalgesia was not significantly different between males and females. $C$, Weight distribution of hindpaws during the course of MIA-induced OA in mice treated with intrathecal injection of IL4-10 FP or PBS at day 21. Two-way ANOVA with Sidak's post hoc. i.t., Intrathecal. ${ }^{*} p<0.05 ;{ }^{* *} p<0.01$; ${ }^{* * *} p<0.001$.

2.402, $p=0.0003$ ) or weight bearing (Fig. $5 G ; F_{(8,48)}=2.870, p=$ $0.0108)$, whereas M0 macrophages did not have any effect.

\section{Inhibition of M1-like macrophages resolves OA pain}

To further assess whether pharmacological inhibition of M1-like macrophages in the DRG resolves persistent OA pain, we tested whether a fusion protein (FP) of the anti-inflammatory cytokines IL4 and IL10 (IL4-10 FP), which has anti-nociceptive effect in inflammatory and neuropathic pain models, could reskew DRG pain-promoting macrophages and resolve OA pain (Eijkelkamp et al., 2016; Steen-Louws et al., 2019). Intrathecal injection of the IL4-10 FP protein in mice with established MIA-induced OA pain, significantly reduced expression of iNOS in DRG infiltrating macrophages $48 \mathrm{~h}$ after the injection $\left(F_{(1,20)}=5.414, p=\right.$ 0.0306; Fig. 6A). IL4-10 FP also resolved the persistent mechanical hyperalgesia and deficit in weight bearing at $48 \mathrm{~h}$ after IL4-10 FP administration $\left(B, F_{(27,264)}=3.449, p<0.001 ; C, F_{(4,24)}=\right.$ 3.770, $p=0.0162$; Fig. $6 B, C)$. IL4-10 FP induced pain resolution was similar in males and females $\left(F_{(8,50)}=0.4040, p=0.9130\right.$; Fig. 6B). Overall, these data indicate that inhibiting DRG infiltrated M1-like macrophages using the IL4-10 FP resolves OAinduced persistent pain.

\section{Discussion}

In this study we identified a key role for DRG macrophages in the maintenance of $\mathrm{OA}$ pain. We unraveled that during the course of OA, macrophages accumulate in the DRG, innervating the damaged knee, and acquire an M1 phenotype. Importantly, these DRG macrophages maintain pain independent from the damage in the knee joint. We found that DRG sensory neurons that innervate the damaged knee program macrophages toward an $\mathrm{M} 1$ phenotype, a phenomenon that is independent of $\mathrm{Na}_{\mathrm{v}} 1.8$ nociceptors. Intriguingly, established OA pain is treated by local depletion of DRG macrophages or by inhibition of M1 macrophages either using M2 macrophages or a fusion protein of IL410. Overall, these data indicate that macrophages are key players in the regulation of osteoarthritis pain and that these cells can be modulated to treat pain.
Over recent years it has become clear that macrophages regulate neuropathic and inflammatory pain at various levels. Macrophages contribute to pain at the site of inflammation in a complete Freund's adjuvant (CFA) model of inflammatory pain or at the site of injury after an incision (Ghasemlou et al., 2015; $\mathrm{Yu}$ et al., 2020). Here, we show for the first time that macrophages also accumulate in the DRG after joint damage in both mice and rats and contribute to the maintenance of OA pain. Importantly, we identified that DRG macrophages control OA pain as local depletion of macrophages was sufficient to resolve pain. These data are in line with recent findings that in neuropathic pain, DRG macrophages are critical contributors to the maintenance of pain (Yu et al., 2020). Although some earlier reports indicate that infiltration of macrophages is sex dependent (Liu et al., 2020; Yu et al., 2020), we found that DRG macrophages control OA pain in a sex-independent manner, similar to that in neuropathic pain (Yu et al., 2020). Thus, osteoarthritis pain, similar to neuropathic pain, is controlled by DRG macrophages in both sexes.

The accumulation of DRG macrophages is either the result of proliferation of resident macrophages or infiltration of circulating monocytes. During nerve injury-induced pain, macrophage proliferation contributes to DRG macrophage expansion (Yu et al., 2020). After induction of OA, the major accumulation of DRG macrophages occurred within the first week after knee damage and remained stable over the following 4 weeks. The major part of these macrophages was $\mathrm{CD}_{115}{ }^{+}$(data not shown), suggesting that the increase in macrophages, at least in part, is caused by infiltration of circulating monocytes into the DRG in OA pain. In support of this hypothesis, in models of OA, sensory neurons express chemokines like CCL2, which attract monocytederived macrophages (Miller et al., 2012).

Macrophages are highly plastic and have marked functional heterogeneity (Gordon and Plüddemann, 2017). Although we show here that DRG macrophages maintain OA pain, findings also point toward a pain-resolving role of macrophages (Willemen et al., 2014; Ji et al., 2016; Bang et al., 2018; Raoof et al., 2020). Intrathecal injection of M2 macrophages inhibited OA pain. In contrast, M1 macrophages 
injected intrathecally induce pain hypersensitivity. How M1 macrophages promote pain is not completely understood. Various studies support the idea that M1 macrophages may promote pain through the release of pro-inflammatory cytokines that activate sensory neurons (Arango Duque and Descoteaux, 2014; Atri et al., 2018). For example, in neuropathic pain, macrophages in the DRG release reactive oxygen species but also IL- $1 \beta$, which contribute to the maintenance of pain (Hackel et al., 2013; Kallenborn-Gerhardt et al., 2014; Yu et al., 2020). Importantly, we show that local inhibition of M1 macrophages with IL4-10 FP in the DRG prevents the maintenance of OA pain. Indeed, IL4-10 FP inhibits release of pro-inflammatory mediators by macrophages (SteenLouws et al., 2019). Thus, limiting pro-inflammatory M1 DRG macrophages prevents the maintenance of pain.

The question remains, What drives the M1-like phenotype of DRG macrophages in OA pain? Activated sensory neurons in the DRG or spinal cord release factors such as neuropeptides, neurotransmitters, and/or cytokines like IL- $1 \beta$ and TNF, which may promote macrophage programming to an M1 phenotype (Pineau and Lacroix, 2007; Gao and Ji, 2010; Kroner et al., 2014; Chen et al., 2020). Moreover, following peripheral axon injury, sensory neurons release exosomes containing microRNAs, including miR-21-5p, which program DRG macrophages toward an M1 phenotype (Simeoli et al., 2017). We show that in vitro sensory neurons isolated from OA mice drive the M1 programming of macrophages. Unexpectedly, $\mathrm{Na}_{\mathrm{v}} 1.8$ nociceptors, which are important for inflammatory pain, do not contribute to the attraction nor to the M1 programming of DRG macrophages, suggesting other sensory neurons, similar as in case of neuropathic pain, drive macrophage attraction and polarization. In line with these findings, chemogenetic silencing of $\mathrm{Na}_{\mathrm{v}} 1.8$ neurons did not affect pain behaviors in established destabilization of the medial meniscus model of OA pain (Miller et al., 2016). Thus, possibly A $\beta$ fibers may drive the accumulation and programming of DRG macrophages and the maintenance of pain. Clearly, future research is needed to identify the factors that program DRG macrophages in OA pain.

Beside macrophages, we observed infiltration of neutrophils in the DRG 2-3 weeks after MIA injection. A majority of studies indicate there is no substantial role for neutrophils in the regulation of pain as neutrophil depletion or recruitment of neutrophils into pain-relevant areas did not change the pain thresholds (Rittner et al., 2006; Ghasemlou et al., 2015). In our study the number of neutrophils were returned to the baseline numbers in the DRG 4 weeks after MIA injection while pain was still present, suggesting that DRG neutrophils do not contribute to maintaining OA pain. Neutrophils infiltrate the DRG probably because they are the first cells to respond to acute tissue damage. Some evidence exists that sensory neurons express damage markers such as ATF3 after joint damage (Ferreira-Gomes et al., 2012). ATF3 expression in sensory neurons is mainly elevated early after induction of OA, whereas 4 weeks after MIA injection when we did not observe DRG neutrophils, ATF3 expression is also absent. Thus, possibly neutrophils migrate to the DRG in response to nerve damage caused by injury in the knee joint.

Because of intrathecal injections, we could locally target macrophages without systemically manipulating the immune system, which sometimes may have significant side effects. The importance of macrophages in maintenance of OA pain, indicates that targeting DRG macrophages may be a therapeutic potential to treat OA pain. We showed that OA pain resolved following the depletion of macrophages. OA pain was also attenuated after intrathecal administration of either M2 macrophages or a fusion protein of IL4-10 that both reduced iNOS expression in inflammatory macrophages in the DRG. Similarly, reprogramming macrophages with IL-13 shift M1 macrophages into am M2 phenotype and reverses neuropathic pain (Kiguchi et al., 2017). However, both M2 and IL4-10 FP may also directly target sensory neurons. For example, IL-10 inhibits spontaneous activity of sensory neurons (Krukowski et al., 2016) and the IL4-10 fusion protein acts on microglia and sensory neurons (Eijkelkamp et al., 2016; Prado et al., 2021). Moreover, M2 macrophages resolve pain by transferring mitochondria to sensory neurons (Raoof et al., 2020). Thus, possibly IL4-10 FP or M2 macrophages directly control sensory neurons and, as a consequence, affect macrophage phenotypes. The IL4-10 FP has also been shown to have direct pain relieving and chondroprotective effects in large animal models (Steen-Louws et al., 2018; van Helvoort et al., 2019). Clearly, these data point to important novel strategies to control OA pain.

The current treatments to resolve OA pain often fail or have significant side effects. OA pain can become independent from the pathologic changes in the joint, suggesting that mechanisms other than the joint damage contribute to pain. Here, we provide a conceptual framework that DRG macrophages control OA pain independent of the damage in the joint. As such, these macrophages represent an interesting target to treat OA chronic pain. Such novel therapeutic strategies should focus on reprogramming the DRG macrophages and may include the fusion protein of IL4-10 or potentially even cell-based therapies that reprogram inflammatory macrophages in the DRG.

\section{References}

Abrahamsen B, Zhao J, Asante CO, Cendan CM, Marsh S, Martinez-Barbera JP, Nassar MA, Dickenson AH, Wood JN (2008) The cell and molecular basis of mechanical, cold, and inflammatory pain. Science 321:702-705.

Adães S, Almeida L, Potes CS, Ferreira AR, Castro-Lopes JM, Ferreira-Gomes J, Neto FL (2017) Glial activation in the collagenase model of nociception associated with osteoarthritis. Mol Pain 13:1744806916688219.

Arango Duque G, Descoteaux A (2014) Macrophage cytokines: involvement in immunity and infectious diseases. Front Immunol 5:491.

Arendt-Nielsen L, Simonsen O, Laursen MB, Roos EM, Rathleff MS, Rasmussen S, Skou ST (2018) Pain and sensitization after total knee replacement or nonsurgical treatment in patients with knee osteoarthritis: identifying potential predictors of outcome at 12 months. Eur J Pain 22:1088-1102.

Atri C, Guerfali FZ, Laouini D (2018) Role of human macrophage polarization in inflammation during infectious diseases. Int J Mol Sci 19:1801.

Bang S, Xie YK, Zhang ZJ, Wang Z, Xu ZZ, Ji RR (2018) GPR37 regulates macrophage phagocytosis and resolution of inflammatory pain. J Clin Invest 128:3568-3582.

Beswick AD, Wylde V, Gooberman-Hill R, Blom A, Dieppe P (2012) What proportion of patients report long-term pain after total hip or knee replacement for osteoarthritis? A systematic review of prospective studies in unselected patients. BMJ Open 2:e000435.

Bourane S, Grossmann KS, Britz O, Dalet A, Del Barrio MG, Stam FJ, Garcia-Campmany L, Koch S, Goulding M (2015) Identification of a spinal circuit for light touch and fine motor control. Cell 160:503-515.

Chaplan SR, Bach FW, Pogrel JW, Chung JM, Yaksh TL (1994) Quantitative assessment of tactile allodynia in the rat paw. J Neurosci Methods 53:5563.

Chen O, Donnelly CR, Ji RR (2020) Regulation of pain by neuro-immune interactions between macrophages and nociceptor sensory neurons. Curr Opin Neurobiol 62:17-25.

Conaghan PG, Cook AD, Hamilton JA, Tak PP (2019) Therapeutic options for targeting inflammatory osteoarthritis pain. Nat Rev Rheumatol 15:355-363.

Creamer P, Hunt M, Dieppe P (1996) Pain mechanisms in osteoarthritis of the knee: effect of intraarticular anesthetic. J Rheumatol 23:1031-1036. 
de Visser HM, Weinans $\mathrm{H}$, Coeleveld $\mathrm{K}$, van Rijen MH, Lafeber FP, Mastbergen SC (2017) Groove model of tibia-femoral osteoarthritis in the rat. J Orthop Res 35:496-505.

de Visser HM, Korthagen NM, Müller C, Ramakers RM, Krijger GC, Lafeber F, Beekman FJ, Mastbergen SC, Weinans H (2018) Imaging of folate receptor expressing macrophages in the rat groove model of osteoarthritis: using a new DOTA-folate conjugate. Cartilage 9:183-191.

de Visser HM, Sanchez C, Mastbergen SC, Lafeber F, Henrotin YE, Weinans $\mathrm{H}$ (2019) Fib3-3 as a biomarker for osteoarthritis in a rat model with metabolic dysregulation. Cartilage 10:329-334.

Eijkelkamp N, Heijnen CJ, Willemen HL, Deumens R, Joosten EA, Kleibeuker W, den Hartog IJ, van Velthoven CT, Nijboer C, Nassar MA, Dorn GW 2nd, Wood JN, Kavelaars A (2010) GRK2: a novel cell-specific regulator of severity and duration of inflammatory pain. J Neurosci 30:2138-2149.

Eijkelkamp N, Steen-Louws C, Hartgring SA, Willemen HL, Prado J, Lafeber FP, Heijnen CJ, Hack CE, van Roon JA, Kavelaars A (2016) IL4-10 fusion protein is a novel drug to treat persistent inflammatory pain. J Neurosci 36:7353-7363.

Ferreira-Gomes J, Adães S, Sousa RM, Mendonça M, Castro-Lopes JM (2012) Dose-dependent expression of neuronal injury markers during experimental osteoarthritis induced by monoiodoacetate in the rat. Mol Pain 8:50.

Gao YJ, Ji RR (2010) Chemokines, neuronal-glial interactions, and central processing of neuropathic pain. Pharmacol Ther 126:56-68.

Ghasemlou N, Chiu IM, Julien JP, Woolf CJ (2015) CD11b+Ly6G- myeloid cells mediate mechanical inflammatory pain hypersensitivity. Proc Natl Acad Sci U S A 112:E6808-6817.

Gordon S, Plüddemann A (2017) Tissue macrophages: heterogeneity and functions. BMC Biol 15:53.

Hackel D, Pflücke D, Neumann A, Viebahn J, Mousa S, Wischmeyer E, Roewer N, Brack A, Rittner HL (2013) The connection of monocytes and reactive oxygen species in pain. PLoS One 8:e63564.

Hannan MT, Felson DT, Pincus T (2000) Analysis of the discordance between radiographic changes and knee pain in osteoarthritis of the knee. J Rheumatol 27:1513-1517.

Hawker GA, Stewart L, French MR, Cibere J, Jordan JM, March L, SuarezAlmazor M, Gooberman-Hill R (2008) Understanding the pain experience in hip and knee osteoarthritis-an OARSI/OMERACT initiative. Osteoarthritis Cartilage 16:415-422.

Hunter DJ, Schofield D, Callander E (2014) The individual and socioeconomic impact of osteoarthritis. Nat Rev Rheumatol 10:437-441.

Jablonski KA, Amici SA, Webb LM, de Dios Ruiz-Rosado J, Popovich PG, Partida-Sanchez S, Guerau-de-Arellano M (2015) Novel markers to delineate murine M1 and M2 macrophages. PLoS One 10:e0145342.

Ji RR, Chamessian A, Zhang YQ (2016) Pain regulation by non-neuronal cells and inflammation. Science 354:572-577.

Kallenborn-Gerhardt W, Hohmann SW, Syhr KM, Schröder K, Sisignano M, Weigert A, Lorenz JE, Lu R, Brüne B, Brandes RP, Geisslinger G, Schmidtko A (2014) Nox2-dependent signaling between macrophages and sensory neurons contributes to neuropathic pain hypersensitivity. Pain 155:2161-2170.

Kiguchi N, Sakaguchi H, Kadowaki Y, Saika F, Fukazawa Y, Matsuzaki S, Kishioka S (2017) Peripheral administration of interleukin-13 reverses inflammatory macrophage and tactile allodynia in mice with partial sciatic nerve ligation. J Pharmacol Sci 133:53-56.

Kroner A, Greenhalgh AD, Zarruk JG, Passos Dos Santos R, Gaestel M, David S (2014) TNF and increased intracellular iron alter macrophage polarization to a detrimental M1 phenotype in the injured spinal cord. Neuron 83:1098-1116.

Krukowski K, Eijkelkamp N, Laumet G, Hack CE, Li Y, Dougherty PM, Heijnen CJ, Kavelaars A (2016) CD8 + T cells and endogenous IL-10 are required for resolution of chemotherapy-induced neuropathic pain. J Neurosci 36:11074-11083.

Lai NY, Musser MA, Pinho-Ribeiro FA, Baral P, Jacobson A, Ma P, Potts DE, Chen Z, Paik D, Soualhi S, Yan Y, Misra A, Goldstein K, Lagomarsino VN, Nordstrom A, Sivanathan KN, Wallrapp A, Kuchroo VK, Nowarski R, Starnbach MN, et al. (2020) Gut-innervating nociceptor neurons regulate Peyer's patch microfold cells and SFB levels to mediate salmonella host defense. Cell 180:33-49 e22.
Lawrence JS, Bremner JM, Bier F (1966) Osteo-arthrosis. Prevalence in the population and relationship between symptoms and x-ray changes. Ann Rheum Dis 25:1-24.

Liu L, Karagoz H, Herneisey M, Zor F, Komatsu T, Loftus S, Janjic BM, Gorantla VS, Janjic JM (2020) Sex differences revealed in a mouse CFA inflammation model with macrophage targeted nanotheranostics. Theranostics 10:1694-1707.

Lluch E, Torres R, Nijs J, Van Oosterwijck J (2014) Evidence for central sensitization in patients with osteoarthritis pain: a systematic literature review. Eur J Pain 18:1367-1375.

Martinez FO, Gordon S (2014) The M1 and M2 paradigm of macrophage activation: time for reassessment. F1000Prime Rep 6:13.

Mathiessen A, Conaghan PG (2017) Synovitis in osteoarthritis: current understanding with therapeutic implications. Arthritis Res Ther 19:18.

Miller RE, Tran PB, Das R, Ghoreishi-Haack N, Ren D, Miller RJ, Malfait AM (2012) CCR2 chemokine receptor signaling mediates pain in experimental osteoarthritis. Proc Natl Acad Sci U S A 109:20602-20607.

Miller RE, Miller RJ, Malfait AM (2014) Osteoarthritis joint pain: the cytokine connection. Cytokine 70:185-193.

Miller RE, Ishihara S, Bhattacharyya B, Menichella D, Miller RJ, Malfait AM (2016) Chemogenetic silencing of Nav1.8-expressing nociceptors reduces pain-related behaviors in a stage-dependent manner in experimental osteoarthritis. Osteoarthritis and Cartilage 24:S9-S9.

Neogi T (2013) The epidemiology and impact of pain in osteoarthritis. Osteoarthritis Cartilage 21:1145-1153.

O’Neill TW, Felson DT (2018) Mechanisms of osteoarthritis (OA) pain. Curr Osteoporos Rep 16:611-616.

Ostojic M, Ostojić M, Prlić J, Soljic V (2019) Correlation of anxiety and chronic pain to grade of synovitis in patients with knee osteoarthritis. Psychiatr Danub 31:126-130.

Pineau I, Lacroix S (2007) Proinflammatory cytokine synthesis in the injured mouse spinal cord: multiphasic expression pattern and identification of the cell types involved. J Comp Neurol 500:267-285.

Pinho-Ribeiro FA, Verri WA Jr., Chiu IM (2017) Nociceptor sensory neuron-immune interactions in pain and inflammation. Trends Immunol 38:5-19.

Pitcher T, Sousa-Valente J, Malcangio M (2016) The monoiodoacetate model of osteoarthritis pain in the mouse. J Vis Exp 16:53746.

Prado J, Popov-Celeketic J, Steen-Louws C, Raoof R, Hack E, Eijkelkamp N (2018) Development of recombinant proteins to treat chronic pain. J Vis Exp 11:57071.

Prado J, Westerink RHS, Popov-Celeketic J, Steen-Louws C, Pandit A, Versteeg S, van de Worp W, Kanters D, Reedquist KA, Koenderman L, Hack CE, Eijkelkamp N (2021) Cytokine receptor clustering in sensory neurons with an engineered cytokine fusion protein triggers unique pain resolution pathways. Proc Natl Acad Sci U S A 118:e2009647118.

Raoof R, Willemen H, Eijkelkamp N (2018) Divergent roles of immune cells and their mediators in pain. Rheumatology (Oxford) 57:429-440.

Raoof R, van der Vlist M, Willemen HLDM, Prado J, Versteeg S, Vos M, Lockhorst R, Pasterkamp RJ, Khoury-Hanold W, Meyaard L, Eijkelkamp N (2020) Macrophages transfer mitochondria to sensory neurons to resolve inflammatory pain. bioRxiv 940445. doi: 10.1101/2020.02. 12.940445.

Renier N, Wu Z, Simon DJ, Yang J, Ariel P, Tessier-Lavigne M (2014) iDISCO: a simple, rapid method to immunolabel large tissue samples for volume imaging. Cell 159:896-910.

Riol-Blanco L, Ordovas-Montanes J, Perro M, Naval E, Thiriot A, Alvarez D, Paust S, Wood JN, von Andrian UH (2014) Nociceptive sensory neurons drive interleukin-23-mediated psoriasiform skin inflammation. Nature 510:157-161.

Rittner HL, Mousa SA, Labuz D, Beschmann K, Schäfer M, Stein C, Brack A (2006) Selective local PMN recruitment by CXCL1 or CXCL2/3 injection does not cause inflammatory pain. J Leukoc Biol 79:1022-1032.

Rutgers M, van Pelt MJ, Dhert WJ, Creemers LB, Saris DB (2010) Evaluation of histological scoring systems for tissue-engineered, repaired and osteoarthritic cartilage. Osteoarthritis Cartilage 18:12-23.

Saqib U, Sarkar S, Suk K, Mohammad O, Baig MS, Savai R (2018) Phytochemicals as modulators of M1-M2 macrophages in inflammation. Oncotarget 9:17937-17950.

Schomberg D, Olson JK (2012) Immune responses of microglia in the spinal cord: contribution to pain states. Exp Neurol 234:262-270. 
Schreiber HA, Loschko J, Karssemeijer RA, Escolano A, Meredith MM, Mucida D, Guermonprez P, Nussenzweig MC (2013) Intestinal monocytes and macrophages are required for $\mathrm{T}$ cell polarization in response to Citrobacter rodentium. J Exp Med 210:2025-2039.

Simeoli R, Montague K, Jones HR, Castaldi L, Chambers D, Kelleher JH, Vacca V, Pitcher T, Grist J, Al-Ahdal H, Wong LF, Perretti M, Lai J, Mouritzen P, Heppenstall P, Malcangio M (2017) Exosomal cargo including microRNA regulates sensory neuron to macrophage communication after nerve trauma. Nat Commun 8:1778.

Steen-Louws C, Popov-Celeketic J, Mastbergen SC, Coeleveld K, Hack CE, Eijkelkamp N, Tryfonidou M, Spruijt S, van Roon JAG, Lafeber F (2018) IL4-10 fusion protein has chondroprotective, anti-inflammatory and potentially analgesic effects in the treatment of osteoarthritis. Osteoarthritis Cartilage 26:1127-1135.

Steen-Louws C, Hartgring SAY, Popov-Celeketic J, Lopes AP, de Smet MBM, Eijkelkamp N, Lafeber F, Hack CE, van Roon JAG (2019) IL4-10 fusion protein: a novel immunoregulatory drug combining activities of interleukin 4 and interleukin 10. Clin Exp Immunol 195:1-9.

Udit S, Burton M, Rutkowski JM, Lee S, Bookout AL, Scherer PE, Elmquist JK, Gautron L (2017) Nav1.8 neurons are involved in limiting acute phase responses to dietary fat. Mol Metab 6:10811091.

van Helvoort EM, Popov-Celeketic J, Eijkelkamp N, Coeleveld K, Tryfonidou MA, Wijne CD, Hack CE, Lafeber F, Mastbergen SC (2019) Canine IL410 fusion protein provides disease modifying activity in a canine model of OA; an exploratory study. PLoS One 14:e0219587.

Vitale I, Manic G, Coussens LM, Kroemer G, Galluzzi L (2019) Macrophages and metabolism in the tumor microenvironment. Cell Metab 30:36-50.

Willemen HL, Eijkelkamp N, Garza Carbajal A, Wang H, Mack M, Zijlstra J, Heijnen CJ, Kavelaars A (2014) Monocytes/macrophages control resolution of transient inflammatory pain. J Pain 15:496-506.

Woolf CJ (2011) Central sensitization: implications for the diagnosis and treatment of pain. Pain 152:S2-15.

Wylde V, Hewlett S, Learmonth ID, Dieppe P (2011) Persistent pain after joint replacement: prevalence, sensory qualities, and postoperative determinants. Pain 152:566-572.

Yu X, Liu H, Hamel KA, Morvan MG, Yu S, Leff J, Guan Z, Braz JM, Basbaum AI (2020) Dorsal root ganglion macrophages contribute to both the initiation and persistence of neuropathic pain. Nat Commun 11:264. 